\title{
PROSPECÇÃO CIENTÍFICA E TECNOLÓGICA DE PRODUTOS DA ESPÉCIE Arrabidaea brachypoda (DC.) BUREAU
}

\author{
SCIENTIFIC AND TECHNOLOGICAL PROSPECTING OF PRODUCTS OF SPECIES
}

Arrabidaea brachypoda (DC.) BUREAU

\author{
Jhone Robson da Silva Costa ${ }^{1}$ \\ Adenilson Pereira Galvão Filho ${ }^{2}$ \\ Thiago Primo Bandeira Citó ${ }^{3}$ \\ Jhônata Costa Moura ${ }^{4}$ \\ Denise Fernandes Coutinho ${ }^{5}$
}

RESUMO: A prospecção científica e tecnológica se apresenta como processo viável para indicar temas de interesse para a pesquisa e desenvolvimento de tecnologias estratégicas para geração de novos produtos e/ou processos nas mais diversas áreas econômicas e sociais. O Brasil apresenta uma das maiores biodiversidades do mundo e suas espécies vegetais podem representar fontes de diversos produtos que podem ser empregados pelo homem, principalmente na busca de novos medicamentos. Dessa forma, este trabalho teve como objetivo identificar as principais atividades farmacológicas de Arrabidaeae brachypoda, seus componentes químicos, além de avaliar as patentes envolvendo essa espécie. Nesse sentido, os extratos das folhas, flores e raízes da espécie apresentam atividade antimicrobiana, anticarcinogênica, antiparasitária, espasmolítica, antiinflamatória, antioxidandte e gastroprotetora. Seus principais componentes químicos são flavonoides, saponinas, triterpenos, taninos, polifenois e óleo essencial. Na prospecção tecnológica, foram identificadas um total de 17 depósitos de patentes nos bancos de dados consultados. Os resultados denotam que o maior volume de patentes está entre os anos de 2010 e 2020, e que os números de publicações científicas superam os depósitos de patentes. Portanto apesar de suas várias propriedades farmacológicas cientificamente comprovadas, ainda há um número pequeno de patentes depositadas de produtos de A. brachypoda.

Palavras-chave: Efeitos farmacológicos. Uso medicinal. Arrabidaea brachypoda.

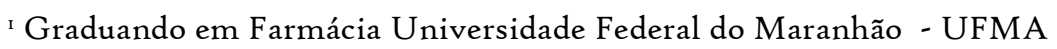

${ }^{2}$ Graduando em Farmácia Universidade Federal do Maranhão - UFMA

${ }^{3}$ Graduando em Farmácia Universidade Federal do Maranhão - UFMA

${ }^{4}$ Graduando em Farmácia Universidade Federal do Maranhão - UFMA

5 Farmacêutica, com habilitação em Bioquímica pela Universidade Federal do Maranhão (1994), especialista em Fitoquímica pela Universidade Federal do Maranhão (1996), mestra em Saúde e Ambiente pela Universidade Federal do Maranhão (1999), doutora em Produtos Naturais e Sintéticos Bioativos pela Universidade Federal da Paraíba (2006). Pós-doutora pela Universidade da California, Los Angeles (UCLA), EUA. Professora do Departamento de Farmácia da Unidade Federal do Maranhão. Universidade Federal do Maranhão - UFMA
} 
ABSTRACT: Scientific and technological prospecting presents itself as a viable process to indicate topics of interest for the research and development of strategic technologies for the generation of new products and/or processes in the most diverse economic and social areas. Brazil has one of the greatest biodiversity in the world and its plant species can represent sources of various products that can be used by man, mainly in the search for new medicines. Thus, this work aimed to identify the main pharmacological activities of Arrabidaeae brachypoda, its chemical components, in addition to evaluating the patents involving this species. In this sense, the extracts of the leaves, flowers and roots of the species present antimicrobial, anticarcinogenic, antiparasitic, spasmolytic, antiinflammatory, antioxidizing and gastroprotective activities. Its main chemical components are flavonoids, saponins, triterpenes, tannins, polyphenols and essential oil. In technological prospecting, a total of 17 patent deposits were identified in the consulted databases. The results show that the largest volume of patents is between the years 2010 and 2020, and that the number of scientific publications exceeds patent deposits. Therefore, despite its several scientifically proven pharmacological properties, there are still a small number of patents filed for A. brachypoda products.

Keywords: Pharmacological effects. Medicinal use. Arrabidaea brachypoda.

\section{INTRODUÇÃO}

O uso de plantas medicinais na terapêutica acompanha o homem através do tempo, sendo predominante em algumas culturas. Durante gerações, os diversos povos tinham as plantas como única forma de tratamento para as doenças. O conhecimento desse poder terapêutico foi se propagando através dos séculos, e muitas populações tradicionais incentivam o seu uso por serem de fácil acesso principalmente em países com há problemas de assistência médica e farmacêutica. A tradicionalidade do uso de plantas medicinais no Brasil resultou de informações e influência da cultura indígena, africana e europeia (BADKE, 2016).

O Brasil apresenta uma das maiores biodiversidades do planeta, conta com aproximadamente $22 \%$ de todas as angiospermas, mesmo com altos índices de devastação que ocorre com os biomas nacionais, apresentando uma variedade de plantas, que usualmente são empregadas na medicina popular. Dessas espécies vegetais, apenas poucas foram submetidas a estudos químico, farmacológico e/ou de toxicidade. Mediante a isso, atualmente já existem debates sobre a exploração sustentável da biodiversidade brasileira, mesmo em uma era pós-genômica. Esse tema mostra-se recorrente e tem destaque mundial na busca de novos fármacos (RESENDE, 2017).

O incentivo de grandes indústrias farmacêuticas para a utilização de medicamentos obtidos de fármacos sintéticos no mundo globalizado, não foi o suficiente para a população 
não utilizar práticas terapêuticas alternativas no cuidado com a saúde, como o uso de plantas medicinais. A ocorrência desse fato deve-se ao alto custo de medicamentos industrializados e pelo fato da idealização de que as plantas possuírem menos efeitos colaterais quando utilizadas no tratamento das doenças (BADKE, 2016). Mesmo oferecendo vantagens na sua utilização, as plantas precisam ser submetidas a estudos científicos que possam comprovar sua eficácia e segurança, para, só então, serem empregadas na terapêutica (SANTOS et al., 2oII).

Nesse contexto, o Brasil destaca-se por apresentar um potencial elevado para o desenvolvimento de produtos provenientes de produtos naturais, considerando que o país possui uma das maiores biodiversidades do planeta, elevando-o ao posto de principal nação entre os 17 países megadiversos (BRASIL, 2018), além de possuir uma cultura étnica que garante o conhecimento tradicional do uso terapêutico desses produtos. Dentre as inúmeras espécies da nossa biodiversidade, destacam-se as pertencentes à família Bignoniaceae, que apresenta cerca de 120 gêneros e 800 espécies de portes arbóreos, arbustivos, além trepadeiras. O Brasil é considerado o centro de diversidade da família, apresentando 32 gêneros e 350 espécies, com distribuição ampla em diversos ecossistemas (CHAGAS JUNIOR, 2010; LOHMANN, 2015; ZAPPI et al., 2015).

O gênero Arrabidaea, ocorre entre países como México, Argentina e no cerrado do Brasil. As espécies desse gênero são bastante utilizadas na medicina tradicional como adstringentes, anti-inflamatórios, antimicrobianos e anti-tumorais (LEITE et al., 2006; MARTIN et al., 2008, ROCHA et al., 2015; RODRIGUES et al., 2019). Dessa forma, destaca-se a espécie A. brachypoda, largamente empregada com finalidades terapêuticas pela população da região centro-oeste do Brasil, contra cálculos renais e dor nas articulações (ROCHA et al., 20II). Essa espécie, é conhecida no Brasil como "cervejinha do campo", “cipó-una” ou "tintureiro”. É um arbusto que ocorre no Cerrado brasileiro, possui entre I,o e 2,o $\mathrm{m}$ de altura, abundantemente ramificado, com folhas simples e flores roso-roxas em inflorescências terminais (ALCERITO et al., 2002; GARCIA, 2008). Esta espécie apresenta como sinonímia Fridericia platyphylla (Cham.) L.G. Lohmann e Xylophragma platyphyllum (DC) L.G. Lohmann (TROPICOS, 2021).

Além disso, alguns relatos da literatura de extrato etanólico das raízes de A. brachypoda apresenta ação anti-inflamatória em ratos e atividade antinociceptiva em 
camundongos (ROCHA et al., 20II). Segundo Alves \& Pereira (20II), os extratos etanólicos das raízes, caule e folhas de A. brachypoda apresentam também atividade leishmanicida para as formas promastigotas de Leishmania amazonensis. Do mesmo modo, o extrato de caule e frutas desta mesma espécie revelou atividade antiviral (BRANDÃO et al., 2010).

Assim, aponta-se que estudos de prospecção são importantes, pois constituem um meio sistemático de mapear desenvolvimentos científicos e tecnológicos futuros capazes de influenciar de forma significativa uma indústria, a economia ou a sociedade como um todo (SECTES, 2009). Considera-se assim que os estudos prospectivos, ou de prospecção tecnológica, buscam agregar valor às informações sobre um recurso com potencial para inovação, na identificação de rumos e oportunidades futuras para os diversos campos sociais, de tal forma que as decisões tomadas sejam mais solidamente baseadas no conhecimento tácito e explícito disponível (COELHO, 2003; SANTOS et al., 2004) e os de prospecção científica mostram todos os estudos que alicerçam a utilização de seus produtos pelo homem (PARANHOS e RIBEIRO, 2018).

No entanto, há uma falta de informações ou, quando existem, estão dispersas o que dificulta a realização de avanços em todas as áreas de conhecimento. Devido ao crescente uso da informação para tomada de decisão, esta tem merecido, cada vez mais, a atenção de gestores, profissionais e pesquisadores. Do lado da demanda, tanto para os clientes quanto para as organizações, a obtenção e uso da informação se torna cada vez mais um processo crítico para o seu desempenho (BARBOSA, 2008).

Neste aspecto, as bases de artigos científicos e patentes se mostram como ricas fontes de informação acadêmicas e tecnológica, as quais são estruturadas e podem ser acessadas a qualquer momento de qualquer parte do mundo. Contudo, no Brasil, este tipo de repositório ainda é pouco explorado pelas instituições, universidades, centros de pesquisa e até mesmo empresas, antes de iniciar suas pesquisas, projetos ou desenvolver seus produtos (PEREIRA et al., 2015). Diante do exposto e considerando a importância da flora brasileira, este trabalho teve como objetivo realizar uma revisão das propriedades farmacológicas, fitoquímicas e tecnológicas relacionadas à espécie Arrabidaea brachypoda (DC.) Bureau. 


\section{METODOLOGIA}

Em relação aos procedimentos metodológicos, foi realizada uma revisão integrativa de literatura, que buscou produção de conhecimento cientifico e tecnológico da espécie $A$. brachypoda. Para o levantamento de estudos científicos, os pontos norteadores foram: distribuição dos artigos segundo os descritores utilizados a espécie em estudo; composição fitoquímica das folhas, flores e raízes; uso medicinal e efeitos farmacológicos e de toxicidade da espécie A. brachypoda.

A consulta aos trabalhos científicos foi feita através de pesquisa às bases de dados Scielo, PubMed e Medline, usando como descritores "Arrabidaea brachypoda", "Xylophragma platyphyllum “ ou "Fridericia platyphylla”, "farmacologia”, "toxicidade” e "química" na língua portuguêsa, espanhola e na língua inglesa. Os critérios de inclusão foram artigos publicados em revistas especializadas e indexadas; artigos publicados no período de 2010 a 2020; e artigos que descrevem a composição, ação farmacológica, toxicidade, além da descrição de seu uso popular na prática medicinal. Foram excluídos trabalhos inferiores ao período estabelecido, que não estiveram completamente disponíveis, artigos que não apresentavam resumos, artigos que não estava relacionado com o tema em estudo, artigos que não estivessem na língua portuguesa, espanhola ou inglesa. Foram buscadas em todos os campos ou índices contendo ("all fields") e título do artigo, resumo e palavras chaves ("article title, absract, keywords").

Para a prospecção tecnológica, foram feitas consultas na base de dados de patentes como o Instituto Nacional de Propriedade Industrial do Brasil (INPI), e nas bases internacionais, "European Patent Office" (Espacenet), "United States Patent and Trademark Office" (USPTO) e "World Intellectual Property Organization" (WIPO), usando as palavras-chaves "Arrabidaea brachypoda", Xylophragma platyphyllum ou "Fridericia platyphylla" no título, resumo e reinvindicações. Os critérios de inclusão foram o tempo de 2010 a 2020. Em seguida os resultados foram agrupados e analisados com auxílio das seguintes ferramenta: evolução temporal, principais depositantes, principais países depositantes, e principais utilizações.

Os resultados foram analisados de forma descritiva e organizados em gráficos no programa Microsoft Office Excel 2016, para discussão das possibilidades tecnológicas apresentadas pela pesquisa. 


\section{RESULTADOS E DISCUSSÕES}

Para o descritor "Arrabidaea brachypoda" foram encontrados 69 artigos publicados nos mais diversos bancos de dados, tanto em periódicos nacionais como nos internacionais. A base Bireme que é nacional apresentou a terceira maior quantidade de artigos publicado para o tema pesquisado (Tabela I). Sabe-se que o Brasil está entre os países que mais produzem pesquisas no mundo, ocupando o $3^{\circ}$ lugar em acesso aberto (GUIMARÃES, 2018). Para o descritor "Arrabidaea brachypoda and pharmacology", na base de dados Bireme não foi detectado nenhuma publicação (Tabela I). Já para o descritor, Fridericia platyphylla sinonímia de Arrabidaea brachypoda, foram encontrados 3 artigos nas bases de dados Pubmed e science direct e dois artigos na base de dados scopus.

Dessa forma, observa-se que os artigos publicados envolvendo a espécie A. brachypoda são publicados principalmente em períodos internacionais. Além disso, apesar do nome mais aceito para a espécie seja F. platyphylla, a maior parte das publicações relacionadas a espécie são feitas pelo nome de A. brachypoda. Aponta-se também, que há um número bem pequeno de estudos envolvendo a espécie vegetal em detrimento de seu grande potencial biológico, destacando a necessidade de mais estudos para se compreender melhor o potencial farmacológico da espécie.

Tabela I - Número de artigos encontrados usando os descritores da pesquisa

\begin{tabular}{cccccc}
\hline & Scielo & Scopus & Pubmed & Science direct & Bireme \\
\hline $\begin{array}{c}\text { Arrabidaea brachypoda } \\
\begin{array}{c}\text { Arrabidaea brachypoda and } \\
\text { pharmacology }\end{array}\end{array}$ & 2 & I9 & II & 32 & 5 \\
$\begin{array}{c}\text { Fridericia platyphylla } \\
\text { Xylophragma platyphyllum }\end{array}$ & 0 & 0 & 8 & 0 & 0 \\
\hline
\end{tabular}

Fonte: Elaborado pelos próprios autores (202I).

A partir dos resultados, pode se apontar que os estudos químicos identificaram, em diferentes partes da espécie Arrabidadea brachypoda, os flavonoides como componentes principais da espécie. As flores são compostas por flavonoides, principalmente chalconas; as raízes apresentam flavonoides, triterpenos, saponinas, taninos, além de outros 
polifenóis e as folhas apresentam principalmente flavonoides (Tabela 2). Os flavonoides se destacam nesta espécie, sendo representado em praticamente todas as partes do vegetal (ALCERITO et al., 2002; ROCHA et al., 2011; MONTEIRO et. al., 2020; RESENDE et al., 2020), este grupo de compostos fenólicos é um dos mais importantes e diversificados metabólitos secundários. Essa classe está amplamente distribuída por todo o reino vegetal e são conhecidas mais de 4.200 variedades de flavonoides (SIMÕES et al., 2017). Além disso, são responsáveis por importantes atividades biológicas, como, antioxidante (está constitui a atividade mais evidenciada pelos estudos até agora desenvolvidos); atividades antiinflamatória, efeito; atividade contra o desenvolvimento de tumores, anti-hepatotóxica, antiulcerogênica; atividade hormonal, bem como ações antimicrobianas e antivirais (SANTOS et al., 2017). Algumas dessas atividades biológicas descritas para A. brachypoda.

Tabela 2. Composição fitoquímica das folhas, flores, caule e raízes de Arrabidaea brachypoda.

\begin{tabular}{|c|c|c|}
\hline Parte da planta & Composição fitoquímica & Autor \\
\hline Folhas & flavonoides & MONTEIRO et. al., 2020 \\
\hline Flores & $\begin{array}{c}\text { Flavonoides (cholconas), Óleo } \\
\text { essencial }\end{array}$ & $\begin{array}{l}\text { RESENDE et al., 2020, } \\
\text { MENEZES, 2020. } \\
\text { BLATT; SANTOS; }\end{array}$ \\
\hline Cera epicular das folhas & Flavonoides, Terpenóides & $\begin{array}{c}\text { SALATINO, I998, } \\
\text { ALCERITO et al., } 2002\end{array}$ \\
\hline Raízes & $\begin{array}{l}\text { Flavonoides, saponinas, } \\
\text { triterpenos, taninos, polifenois }\end{array}$ & $\begin{array}{l}\text { ROCHA et al., 20II, ROCHA et } \\
\text { al., 2014; ROCHA et al., 2017, } \\
\text { SALGADO et al., } 2020\end{array}$ \\
\hline
\end{tabular}

Fonte: Elaborada pelos próprios autores (202I).

A pesquisa bibliográfica apontou 26 artigos que tratavam de diferentes atividades farmacológicas associadas a espécie A. brachypoda e relacionadas a diferentes órgãos (folhas, flores e raízes) do vegetal, sendo selecionados para compor a Tabela 3. Ressalta-se também efeitos tóxicos descritos para a espécie, constatou-se que um artigo relatou a ação tóxica para essa planta.

A partir da pesquisa bibliográfica foi possível constatar que a espécie A. brachypoda apresenta importantes efeitos farmacológicos e baixa toxicidade que podem constituir uma importante alternativa para o tratamento de diversas patologias, tendo em vista que os medicamentos convencionais alopáticos ainda não são acessíveis em sua totalidade para 
população brasileira, e as plantas medicinais podem ser uma alternativa terapêutica muito atrativa devido a facilidade de acesso (MORORÓ et al., 2020). Dentre os efeitos biológicos comprovados cientificamente estão: atividade antiespasmódica, antioxidante, antiinflamatória, anticarcinogênica, antioxidante (Tabela 3), indicando que essa espécie pode servir para tratamento de várias doenças, além de poder ser uma importante fonte de substâncias bioativas (fitofármacos) ou protótipos para fins terapêuticos. Outras atividades farmacológicas descritas para espécie A. brachypoda são: atividade bactericida, antifúngica e antiparasitária (Tabela 3). Relatos da literatura descrevem esses efeitos como muito promissores, que se bem trabalhos podem levar ao desenvolvimento de bioprodutos, contribuindo para o tratamento de doenças causadas por bactérias, fungos e parasitos (SOUSA et al., 2020; NEUENSCHWANDER, et al., 2020; MENEZES et al., 2020). Considerando esses aspectos, essa planta ganha uma enorme importância, haja vista que os medicamentos usados para tratar infecções por microrganismos, têm induzido o surgimento de cepas resistentes a diversas classes farmacológicas, culminando na diminuição e até perda de eficácia de vários medicamentos (VALDÉS et al., 2017).

Quanto à toxicidade, pesquisas indicam que os extratos das folhas e raízes de $A$. brachypoda induz alterações estrogênicas (Tabela 3), que pode levar a uma desregulação do crescimento, diferenciação e função dos órgãos reprodutivos, bem como do sistema cardiovascular e imune (HELDRING et al., 2007). O Estrógeno e seus receptores estão envolvidos ainda no desenvolvimento e disseminação de vários tumores malignos, uma vez que esses receptores possuem diferentes funções na tumorigênese (MARZAGALLI et al., 2016).

Além disso, os extratos obtidos das folhas, raízes e caule de A. brachypoda apresentam efeitos mutagênicos (Tabela 2). Nessa perspectiva, seu uso deve ser acompanhado por um profissional habilitado, pois a exposição prolongada pode resultar no desenvolvimento de câncer. Entretanto entende-se que os efeitos mutagênicos são dependentes de concentração, sendo necessários mais estudos para avaliar essa atividade tóxica,_e assim estipular parâmetros de segurança e uso para A. brachypoda.

É importante ressaltar a necessidade de ensaios clínicos para completar a validação científica de uma espécie vegetal e para A. brachypoda, não há relatos de estudos clínicos, embora sua avaliação pré-clínica demonstre forte potencial para a sua utilização 
terapêutica, mesmo com os resultados da toxicidade, que podem indicar contra-indicações e tempo de uso determinado.

Os extratos de A. brachypoda são compostos principalmente por uma série de flavonóides, bem como por suas agliconas. Esses compostos fenólicos de A. brachypoda estão provavelmente implicados no potencial mutagênico e estrogênico observado por Resende et al., (2017), tendo em vista que os flavonoides que apresentam atividade mutagênica, possuem em suas estruturas: hidroxila livre na posição 3 do anel C, dupla ligação entre as posições 2 e 3 e grupo ceto na posição 4 (RIETJENS et al., 2005, RESENDE et al., 2012). Algumas dessas características estruturais são exibidas por quatro flavonóides isolados da cera epicular por Alcerito et al. (2002), o que explica os efeitos tóxicos observados (SILVA et al., 2000).

Tabela 3. Efeitos biológicos descritos para espécie Arrabideae brachypoda em ensaios pré-clínicos

\begin{tabular}{|c|c|c|}
\hline Efeito biológico & Parte da planta & Autor \\
\hline Atividade antifúngica & Flores & MENEZES et al., 2020 \\
\hline Atividade leishimanicida & Raízes e folhas & $\begin{array}{l}\text { NEUENSCHWANDER, et al., 2020, } \\
\text { ROCHA et al., 2019, ROCHA et al., 2014, } \\
\text { PEREIRA, 20II }\end{array}$ \\
\hline Atividade antiparasitária & Raízes & NEUENSCHWANDER, et al., 2020. \\
\hline Atividade antimicrobiana & Flores & $\begin{array}{l}\text { SOUSA et al., 2020; RESENDE et al., } \\
2020\end{array}$ \\
\hline Atividade espasmolítica & Folhas & MONTEIRO et al., 2020 \\
\hline $\begin{array}{l}\text { Atividade inibidora de } \\
\text { lipoxigenase }\end{array}$ & Ramos & BERTANHA et al., 2020 \\
\hline Anticarcinogênica & Raízes & RODRIGUES et al., 2019 \\
\hline Antinoceptiva & Raízes & $\begin{array}{l}\text { RODRIGUES et al., 2017, ROCHA et al } \\
\text { 2orI. }\end{array}$ \\
\hline Atividade gastroprotetora & Raízes & ROCHA et al., 2017 \\
\hline Atividade mutagênica & Folhas, raízes e caule & RESENDE et al., 2017 \\
\hline Atividade estrogenicida & Folhas e raízes & RESENDE et al., 2017 \\
\hline Atividade Antiinflamatório & Raízes & ROCHA et al., 2015, ROCHA et al., 20II. \\
\hline Atividade antiulcerogênica & - & VILEGAS, 2015 \\
\hline Atividade antioxidante & Folhas & PEREIRA, 2012 \\
\hline Atividade antiproteolítica & Folhas & PEREIRA, 2012 \\
\hline Atividade antiviral & Folhas & BRANDÃO et al., 2010 \\
\hline
\end{tabular}

Fonte: Elaborada pelos próprios autores (2021). 
Compreendendo que o potencial biológico de uma espécie vegetal, pode culminar no desenvolvimento de tecnologias envolvendo a planta foi realizada uma prospecção tecnológica com finalidade de apontar essas inovações. A partir da prospecção tecnológica realizada para a espécie A. brachypoda resultou num total de 36 depósitos de patentes nos bancos de dados consultados. Pode-se observar que a base WIPO apresentou o maior número de documentos para a tecnologia “A. brachypoda” com 19 patentes encontradas. Seguida da base de patentes Espacenet, apresentando io patentes, na base de dados INPI, foram encontradas 4 patentes usando os descritores apresentados na tabela 3. Já na base de dados USPTO foi realizado apenas um pedido de patente (Tabela 4 ).

Os estudos de Prospecção Tecnológica são de fundamental importância e constituem a ferramenta básica para orientar os esforços empreendidos para o desenvolvimento de tecnologias. Atualmente, esses estudos representam subsídios fundamentais para ampliar a capacidade de antecipação e organização dos sistemas de inovação, tanto no meio empresarial, quanto no âmbito acadêmico (ROCHA et al., 2020).

As informações tecnológicas extraídas dos documentos de patentes são importantes indicadores das atividades relacionadas a Pesquisa, Desenvolvimento e Inovação (PD\&I) e aos avanços tecnológicos na área da ciência e tecnologia (SANTOS \& KALID, 2020). Nesse sentido, foram encontrados 36 pedidos de patentes, que após análise e leitura resultou num total de 18 registros de patente.

Tabela 4. Número de patentes por descritores nas bases de dados utilizadas para a pesquisa

\begin{tabular}{|c|c|c|c|c|c|}
\hline Palavras-chave & INPI & Espacenet & USPTO & WIPO & Total \\
\hline Arrabidaea brachypoda & 4 & 4 & I & 9 & I8 \\
\hline Fridericia platyphylla & o & o & 0 & 0 & O \\
\hline $\begin{array}{c}\text { "cipó-una" or "cervejinha do } \\
\text { campo" }\end{array}$ & o & 2 & o & 4 & 4 \\
\hline $\begin{array}{l}\text { Arrabidaea brachypoda and } \\
\text { pharmaceutical composition }\end{array}$ & o & 4 & o & IO & I4 \\
\hline total & 4 & IO & I & I9 & 36 \\
\hline
\end{tabular}


Nota: INPI - Instituto Nacional da Propriedade Industrial, Espacenet - Escritório Europeu de Patentes, USPTO - Escritório de Patentes e Marcas dos Estados Unidos, WIPO Organização Mundial da Propriedade Intelectual.

Fonte: INPI, Espacenet, USPTO e WIPO.

Após análise das patentes, encontradas para cada descritor, obteve-se 17 depósitos de patentes nos bancos de dados consultados envolvendo a planta A. brachypoda, sendo o WIPO o banco com maior número de patentes encontradas, com 9 patentes, seguido pelo INPI e EPO, com 4 patentes, e o USPTO (Figura I). Dentre os 17 registros de patente encontrados, o Brasil e a Suíça lideram com ro patentes depositadas, uma vez que os dois países foram parceiros no desenvolvimento dos processos e produtos envolvendo a planta A. brachypoda (Figura I). Esses dados podem estar relacionados ao fato da espécie vegetal ter ocorrência em grande parte do território brasileiro e devido seu uso na medicina popular, fatores que despertam o interesse em estudar a espécie vegetal (ALCERITO et al., 2002).

Figura I. Número de patentes depositadas nas bases de dados com a tecnologia Arrabidaea brachypoda.

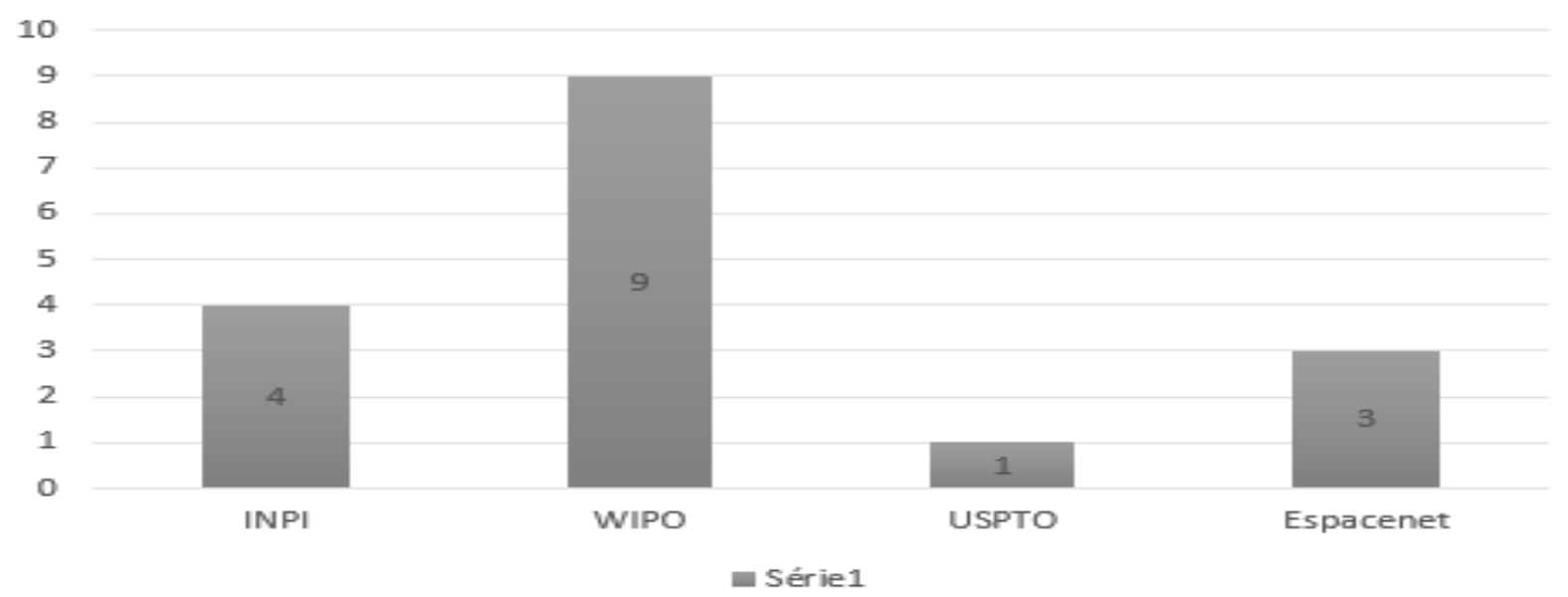

Fonte: INPI, Espacenet, USPTO e WIPO.

Nota: INPI - Instituto Nacional da Propriedade Industrial, Espacenet - Escritório Europeu de Patentes, USPTO - Escritório de Patentes e Marcas dos Estados Unidos, WIPO Organização Mundial da Propriedade Intelectual. 
Nos últimos io anos, observou-se que o maior número de patentes foi depositado entre os anos de 2013 e 2015 (Figura 2), demonstrando o crescente aumento no interesse tecnológico pela planta em estudo. $\mathrm{Na}$ Figura 3, também é possível observar que, de 2010 a 2012, não houve patentes depositadas. Já no ano de 2014 e 2016, uma patente foi depositada; e em 2017, 3 patentes. Essa evolução nos pedidos de patentes, nos últimos anos, enfatiza o potencial econômico da espécie. Depois desse período, verificou-se que nos anos de 2018 a 2020, não houve pedidos de patente registrados (Figura 2).

Em contrapartida, notou-se que nos últimos anos, o número de patentes caiu de maneira significativa para a espécie em estudo, chegando a zero. Isso pode estar associado aos baixos investimentos em pesquisa no Brasil, que tem culminado num menor desenvolvimento tecnológico no pais (ARBIX, 2017). A redução no interesse da indústria pela biodiversidade, devido a fatores técnicos e políticos, pode ser outro motivo (PIMENTEL et al., 2015).

Figura 2 - Evolução anual dos pedidos de patentes depositados nas bases de dados com Arrabidaea brachypoda.

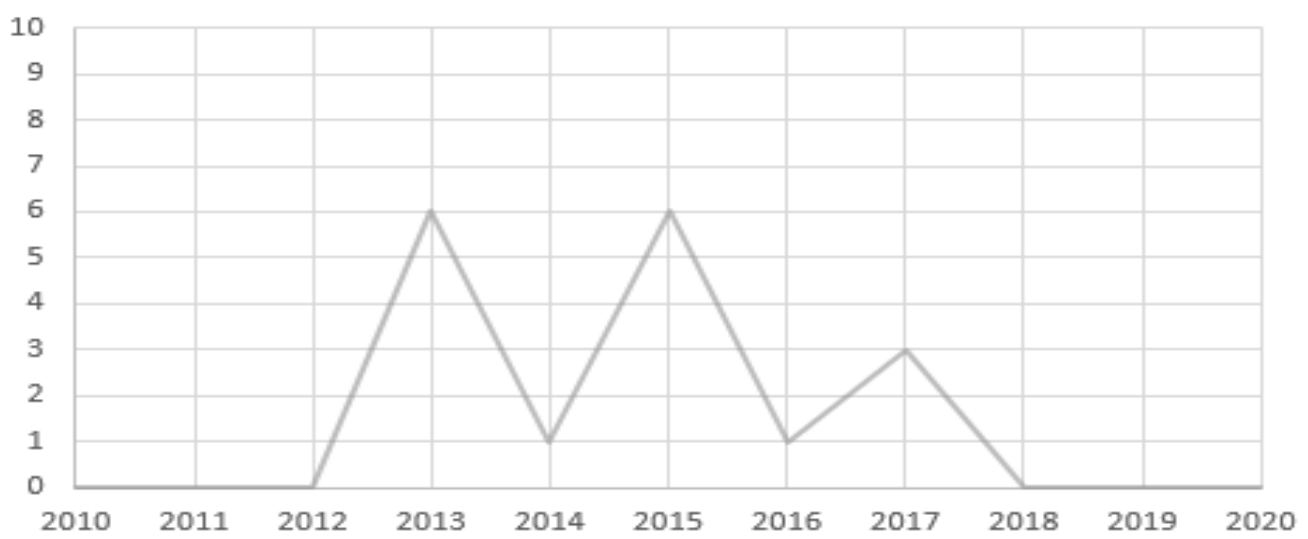

Fonte: INPI, Espacenet, USPTO e WIPO.

Dentre os depósitos de patentes pesquisados, 7 foram classificados no código IPC A6IK 3I, que abrange as preparações com finalidades médicas, odontológicas ou higiênicas. Seguida por A6IK 36 (atividade terapêutica específica de compostos químicos ou preparações medicinais), com 7 das patentes. Outras classes importantes foram $\mathrm{Co}_{7} \mathrm{D} 3 \mathrm{II}$ (Compostos heterocíclicos contendo anéis de seis membros tendo um átomo de oxigênio 
como o único heteroátomo, condensado com outros anéis), Co7D 405 (Compostos heterocíclicos contendo no sistema condensado pelo menos um heteroanel tendo átomos de enxofre como os únicos heteroátomos do anel) e Co7D 495 (Compostos heterocíclicos contendo um ou mais heteroanéis tendo átomos de oxigênio como os únicos heteroátomos do anel e um ou mais anéis tendo nitrogênio como o único heteroátomo do anel ), com uma cada CIP (classificação internacional). Estas informações estão descritas na Figura 3.

A biodiversidade é hoje considerada uma fonte natural sofisticada de estruturas químicas, a qual apresenta grande potencial para o desenvolvimento de inovações em vários setores, como farmacêutico, cosmético, agroquímico e alimentício. Vários são os entraves que colaboram para o aproveitamento inadequado da biodiversidade brasileira, $e$ autores justificam que a regulamentação de proteção ao patrimônio genético e de repartição de benefícios no Brasil tem provocado dificuldades nas pesquisas sobre a diversidade biológica e química. Em consoante a isso, novas legislações têm trazido discussões na relação entre o setor acadêmico e econômico sobre a bioeconomia (PIMENTEL et al., 2015; BOLZANI, 2016). Entretanto, o pequeno número de patentes depositadas com finalidades médicas, utilizando A. brachypoda mostra o grande potencial tecnológico e econômico dessa espécie a ser explorado.

Figura 3 - Distribuição por CIP dos pedidos de patentes depositados nos bancos de dados com a planta Arrabidaea brachypoda.

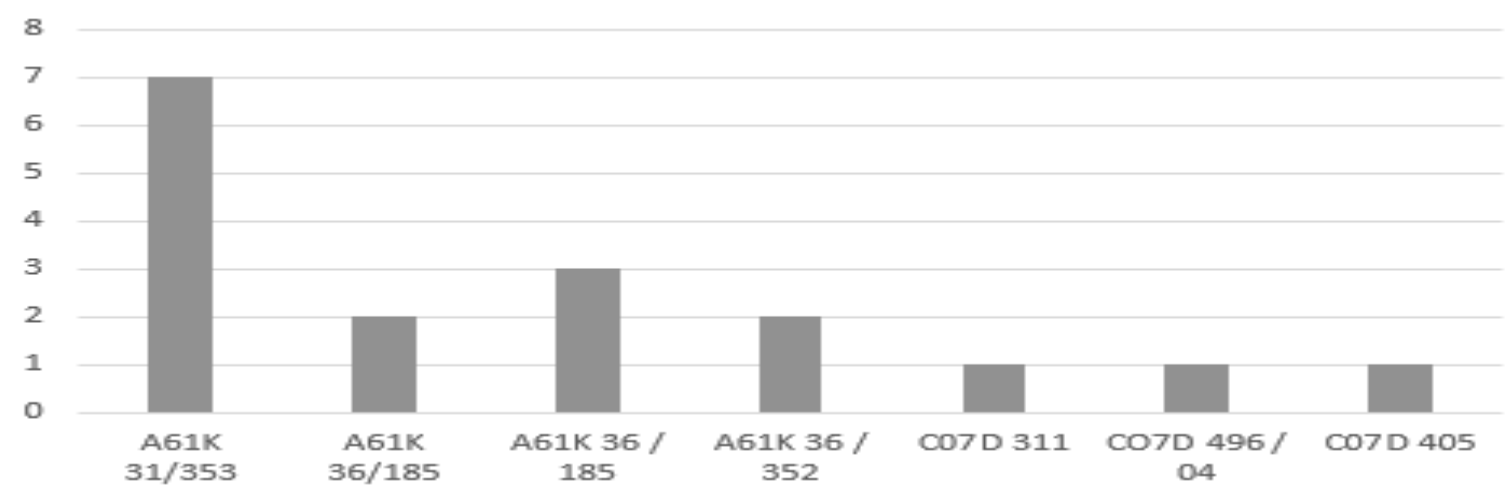

Nota: A6IK 3I/353; A6ıK 36/185; Co7D 3II; CO7D 495/o4; Co7D 405 - Classificação internacional de patentes. Fonte: INPI, Espacenet, USPTO e WIPO. 


\section{CONCLUSÃO}

A partir dessa revisão bibliográfica, ponta-se que o número de publicações sobre o assunto aumentou ao longo do tempo. Porem a espécie Arrabidaea brachypoda ainda é uma espécie pouco estudada e que apresenta um grande potencial para o desenvolvimento de novos produtos com base em suas propriedades. Além disso, os dados apresentados mostram que o uso na medicina popular de A. brachypoda tem encontrado respaldo em alguns estudos científicos, sendo comprovada a eficácia de seus efeitos em investigações experimentais. Dessa maneira, considerando o uso popular de A. brachypoda, esses resultados contribuem para um possível uso dessa planta com finalidade curativa, contudo há necessidade de se avaliar parâmetros relacionadas à segurança quanto ao uso desse vegetal. Por fim, aponta-se a importância e necessidade de mais estudos envolvendo a planta.

\section{REFERÊNCIAS}

ALCERITO, Tatiana et al. Foliar epicuticular wax of Arrabidaea brachypoda: flavonoids and antifungal activity. Biochemical Systematics and Ecology, v. 30, n. 7, p. 677-683, 2002. ALVES, L.; PEREIRA, I.O. Avaliação da atividade leishmanicida de extratos obtidos de diferentes partes de Arrabidaea brachypoda. Revista Iniciação Científica da Universidade Vale do Rio Verde, v. 12, p. 42-42, 2011.

ARBIX, Glauco. Dilemas da inovação no Brasil. POLÍtICAS DE APOIO À INOVAÇÃO TECNOLÓGICA NO BRASIL, p. 47, 2017.

BADKE, Marcio Rossato et al. Saber popular: uso de plantas medicinais como forma terapêutica no cuidado à saúde. Revista de Enfermagem da UFSM, v. 6, n. 2, p. 225-234, 2016.

BARBOSA, R. R. Gestão da informação e do conhecimento: Origens, Polêmicas e Perspectivas. Inf. Inf., v.13, n. esp., p. I-25. 2008.

BERTANHA, Camila S. et al. Isolation, in vitro and in silico Evaluation of Phenylethanoid Glycoside from Arrabidaea brachypoda as Lipoxygenase Inhibitor. Journal of the Brazilian Chemical Society, v. 31, n. 4, p. 849-855, 2020. 
BLATT, Cecília TT; DOS SANTOS, Márcia D.; SALATINO, Antonio. Flavonoids of Bignoniaceae from the "cerrado" and their possible taxonomic significance. Plant systematics and evolution, v. 210, n. 3, p. 289-292, 1998.

BOLZANI, V.S. Biodiversidade, bioprospecção e inovação no Brasil. Ciência e Cultura, v. 68, n. I, p. 4-5, 2016.

BRANDÃO, G.C.; KROON, E.G.; DOS SANTOS, J.R.; STEHMANN, J.R.; LOMBARDI, J.A.; OLIVEIRA, A.B. Antiviral activity of Bignoniaceae species occurring in the State of Minas Gerais (Brazil). Letters in Applied Microbiology, v. 51, n. 4, p. 469476, 2010.

BRASIL. Decreto n. 5813, de 22 de junho de 2006. Política Nacional de Plantas Medicinais. Brasilia, DF.

BRASIL. Ministério do Meio Ambiente. Biodiversidade Brasileira. Ministério do Meio Ambiente, 2018.

Disponível em: 〈http://www.mma.gov.br/biodiversidade/biodiversidadebrasileira〉 CARDOSO, Cássia Regina Primila et al. Mutagenic activity promoted by amentoflavone and methanolic extract of Byrsonima crassa Niedenzu. Toxicology, v. 225, n. I, p. 55-63, 2006.

CHAGAS JUNIOR, José Magno das; CARVAlHO, Douglas Antônio de; MANSANARES, Mariana Esteves. A família Bignoniaceae Juss.(Ipês) no município de Lavras, Minas Gerais. Cerne, v. 16, p. 517-529, 2010.

DA ROCHA, Claudia Quintino et al. Gastroprotective effects of hydroethanolic root extract of Arrabidaea brachypoda: Evidences of cytoprotection and isolation of unusual glycosylated polyphenols. Phytochemistry, v. 135, p. 93-105, 2017.

DA ROCHA, Cláudia Q. et al. Anti-inflammatory and antinociceptive effects of Arrabidaea brachypoda (DC.) Bureau roots. Journal of ethnopharmacology, v. 133, n. 2, p. 396-40I, 2011.

DA ROCHA, Cláudia Quintino et al. Dimeric flavonoids from Arrabidaea brachypoda and assessment of their anti-Trypanosoma cruzi activity. Journal of natural products, v. 77, n. 6, p. 1345-1350, 2014. 
EVANGELISTA A. R. S. (20II). O processo de desmatamento do bioma caatinga: riscos e vulnerabilidades socioambientais no território de identidade do sisal, Bahia. Revista geográfica de América Central, Costa Rica. Número especial EGAL. I3p.

GARCIA, Fernanda. Estudo fitoquímico da fração AcOEt do extrato etanólico das folhas de Arrabidaea brachypoda (DC) Bureau - Bignoniaceae e atividades antioxidante e inibitória da enzima mieloperoxidase das substancias isoladas. 2008. Ioo f. Dissertação (mestrado) - Universidade Estadual Paulista, Instituto de Química, 2008.

GUIMARÃES, M. Brasil é o país com mais publicação científica em acesso aberto. Pesquisa Fapesp, São Paulo, ed. 263, 21 jan. 2018. Disponível em: http://revistapesquisa.fapesp.br/2018/or/2I/brasile-o-pais-com-mais-publicacao-cientificaem-acesso-aberto. Acesso em: 30 jan. 2021.

HELDRING, N. et al. Estrogen receptors: how do they signal and what are their targets. Physiological reviews, v. 87, n. 3, p. 905-931, 2007. ISSN 0031-9333.

LEITE, Joao Paulo V. et al. Trypanocidal activity of triterpenes from Arrabidaea triplinervia and derivatives. Biological and Pharmaceutical Bulletin, v. 29, n. II, p. 23072309, 2006.

LOHMANN, L. G. Bignoniaceae in: Lista de Espécies da Flora do Brasil.vJardim Botânico do Rio de Janeiro. Disponível em:http://floradobrasil.jbrj.gov.br/jabot/floradobrasil/FBir2305.

MARTIN, Frédéric et al. Antioxidant C-glucosylxanthones from the leaves of Arrabidaea patellifera. Journal of natural products, v. 7I, n. II, p. I887-I890, 2008.

MARZAGALLI, M. et al. Estrogen Receptor $\beta$ in Melanoma: From Molecular Insights to Potencial Clinical Utility. Frontiers in Endocrinology, v. 7, n. I40, p. I-15, 2016.

MENEZES FILHO, Antonio Carlos Pereira. Avaliação química, antifúngica e antioxidante do óleo essencial da flor de Fridericia platyphylla (Cham.) LG Lohmann. Scientia Naturalis, v. 2, n. I, 2020.

MESQUiTA MORORÓ, Iara Maria Muniz et al. Desigualdades no acesso a medicamentos no Brasil: um estudo de base populacional. Research, Society and Development, v. 9, n. 10, p. e5319108952-e5319108952, 2020. 
MONTEIRO, De Souza Fabio et al. Hydroalcoholic extract of leaves of Arrabidaea brachypoda (DC.) Bureau present antispasmodic activity mediated through calcium influx blockage. Revista de Ciências Farmacêuticas Básica e Aplicada, v. 4I, p. I-13, 2020.

NEUENSCHWANDER, Alexandra et al. Production of Highly Active Antiparasitic Compounds from the Controlled Halogenation of the Arrabidaea brachypoda Crude Plant Extract. Journal of Natural Products, v. 83, n. 9, p. 2631-2640, 2020.

PARANHOS, Rita de Cássia Santos; RIBEIRO, Núbia Moura. Importância da prospecção tecnológica em base em patentes $\mathrm{E}$ seus objetivos da busca. Cadernos de Prospecção, v. II, n. 5, p. 1274, 2018.

PEREIRA, Ivan de Oliveira. Determinação da atividade leishmanicida, antiproteolítica e antioxidante de Arrabidaea brachypoda. 2012.

PEREIRA, S. A. et al. Prospecção científica e tecnológica do gênero Jatropha (Euphorbiaceae). Cadernos de Prospeç̧ão, Salvador, v. 8, n. 2, p. 355-364, abr.-jun. 2015.

PIMENTEL, V.; VIEIRA, V.; MITIDIERI, T.; FRANÇA, F.; PIERONI, J.P. Biodiversidade brasileira como fonte da inovação farmacêutica: uma nova esperança? Revista do BNDES, v. 43, p. 4I-89, 2015 .

RESENDE, Flávia Aparecida et al. In vitro toxicological assessment of Arrabidaea brachypoda (DC.) Bureau: Mutagenicity and estrogenicity studies. Regulatory Toxicology and Pharmacology, v. 90, p. 29-35, 2017.

RESENDE, Flavia Aparecida et al. Mutagenicity of flavonoids assayed by bacterial reverse mutation (Ames) test. Molecules, v. 17, n. 5, p. 5255-5268, 2012.

REZENDE-JÚNIOR, Luís Mário et al. Chalcones Isolated from Arrabidaea brachypoda Flowers as Inhibitors of NorA and MepA Multidrug Efflux Pumps of Staphylococcus aureus. Antibiotics, v. 9, n. 6, p. 351, 2020.

RIETJENS, Ivonne MCM et al. Flavonoids and alkenylbenzenes: mechanisms of mutagenic action and carcinogenic risk. Mutation Research/Fundamental and Molecular Mechanisms of Mutagenesis, v. 574, n. I-2, p. 124-138, 2005.

ROCHA, Carlos Alberto Machado et al. Prospecção Científica e Tecnológica do Ácido Caurenoico, um Diterpeno Bioativo. Cadernos de Prospecção, v. 13, n. I, p. 256, 2020.

ROCHA, Cláudia Q. da; VILELA, Fabiana C.; CAVALCANTE, Gustavo P.; SANTACECÍlIA, Flávia V.; SANTOS-E-SILVA, Lucas; SANTOS, Marcelo H. dos; GIUSTI- 
PAIVA, Alexandre. Anti-inflammatory and antinociceptive effects of Arrabidaea brachypoda (DC.) Bureau roots. Journal of Ethnopharmacology, [S.L.], v. 133, n. 2, p. 39640I, jan. 2011.

ROCHA, Cláudia Q et al. Oleanane-type triterpenoid: an anti-inflammatory compound of the roots Arrabidaea brachypoda. Revista Brasileira de Farmacognosia, v. 25, n. 3, p. 228232, 2015 .

ROCHA, Claudia Quintino et al. Gastroprotective effects of hydroethanolic root extract of Arrabidaea brachypoda: Evidences of cytoprotection and isolation of unusual glycosylated polyphenols. Phytochemistry, v. 135, p. 93-105, 2017.

ROCHA, Vinícius PC et al. Antileishmanial Activity of Dimeric Flavonoids Isolated from Arrabidaea brachypoda. Molecules, v. 24, n. I, p. I, 2019.

RODRIGUES, Carla Daniele Pinheiro. Avaliação anticancerígena de um flavonóide raro isolado das raízes de Fridericia platyphylla (Cham.) LG Lohmann em linhagem de células de próstata. 2019.

RODRIGUES, Vinícius Peixoto et al. Involvement of opioid system, TRPM8, and ASIC receptors in antinociceptive effect of Arrabidaea brachypoda (DC) bureau. International Journal of Molecular Sciences, v. I8, n. II, p. 2304, 2017.

RODRIGUES, Vinícius Peixoto. Avaliação das atividades antinociceptiva e antiinflamatória do extrato diclorometano das raízes de Arrabidaea brachypoda (dc.) Bureau em camundongos. 2017 .

SANTOS, Ravely L. et al. Análise sobre a fitoterapia como prática integrativa no Sistema Único de Saúde. Revista brasileira de plantas medicinais, v. I3, p. 486-49I, 201 I.

SANTOS, Daniel Sousa; RODRIGUES, Mayara Mikelle Farias. Atividades farmacológicas dos flavonoides: um estudo de revisão. Estação Científica (UNIFAP), v. 7, n. 3, p. 29-35, 2017 .

SANTOS, Fárlei Cosme Gomes; DE ARAÚJO KALID, Ricardo. Prospecção tecnológica: um estudo das tecnologias aplicada ao beneficiamento e derivados do cacau. Research, Society and Development, v. 9, n. 3, p. e56932354-e56932354, 2020.

SERRA VALDÉS, Miguel Ángel. La resistencia microbiana en el contexto actual y la importancia del conocimiento y aplicación en la política antimicrobiana. Revista Habanera de Ciencias Médicas, v. 16, n. 3, p. 402-419, 2017. 
SILVA, I. Duarte et al. Chemical features of flavonols affecting their genotoxicity. Potential implications in their use as therapeutical agents. Chemico-biological interactions, v. I24, n. I, p. 29-51, 2000.

SILVA, M. M.; QUEIROZ, L. P. A família Bignoniaceae na região de Catolés, Chapada Diamantina, Bahia, Brasil. Sitientibus Série Ciências Biológicas, v. 3, n. I/2, p. 3- 2I, 2003. SILVA DANTAS, Fabiana Gomes et al. Mutagenic potential of medicinal plants evaluated by the Ames Salmonella/microsome assay: A systematic review. Mutation Research/Reviews in Mutation Research, p. 108338, 2020.

SIMÕES, C. M. O. et al. Farmacognosia: do produto natural ao medicamento. Porto Alegre: Artmed, 2017.

SINGH, Balwinder et al. Phenolic composition and antioxidant potential of grain legume seeds: A review. Food Research International, v. IoI, p. I-16, 2017.

SOUSA ANDRADE, Leila Maria et al. Antimicrobial activity and inhibition of the NorA efflux pump of Staphylococcus aureus by extract and isolated compounds from Arrabidaea brachypoda. Microbial Pathogenesis, v. I40, p. I03935, 2020.

SOUZA, V.C.; LORENZI, H. Botânica Sistemática. 2 ed. Nova Odessa, SP, Instituto Plantarum. 2008.

TROPICOS.org. Missouri Botanical Garden. 3I May 202I $\langle$ https://tropicos.org/name/ıoig3256>

(C) 2021 Missouri Botanical Garden - 4344 Shaw Boulevard - Saint Louis, Missouri 63110 VILEGAS, Wagner et al. Uso de compostos obtidos a partir de extratos da Arrabidaea Brachypoda como antiulcerogênico. 2015.

ZAPPI, Daniela C. et al. Growing knowledge: an overview of Seed Plant diversity in Brazil. Rodriguésia, Rio de Janeiro, v. 66, n. 4, p.1085-1113, 2015. 